\title{
Analysis of viral diversity in stool samples from infants and children with acute gastroenteritis in Kuwait using Metagenomics approach
}

Hawraa Adel Mohammad, Nada Mohammed Madi ${ }^{*}$ and Widad Al-Nakib

\begin{abstract}
Background: Current molecular target-dependent methods are used to detect only known viruses. However, metagenomics based on next-generation sequencing (NGS) technique is a target-independent assay that enables simultaneous detection and genomic characterisation of all microorganisms present in a sample. In this study, we aimed to develop a metagenomics approach using NGS to identify and characterise viruses in stool samples from infants and children with Acute Gastroenteritis (AGE) in Kuwait.
\end{abstract}

Methods: We have investigated 84 stool samples from infants and children aged one month to ten years old with signs and symptoms of gastroenteritis who attended Mubarak Al-Kabeer and Al-Amiri hospitals in Kuwait from January to December 2017. A metagenomics approach using NGS to characterise viruses in clinical samples was used. Also, the commercial Real-Time PCR assay was used to detect viruses causing gastroenteritis.

Results: Metagenomics analysis revealed an average of 280,768 reads in which $5 \%$ of the reads were derived from viruses. The analysis of viral sequences verified that single infection of human adenovirus was the leading cause of gastroenteritis among infants and children, which was detected in $23.2 \%$ of the patients, followed by a mixed infection of human adenovirus and other viruses, which was detected in 20.9\% of patients. Also, the newly discovered viruses known to cause gastroenteritis were detected, such as astrovirus MLB2, primate bocaparvovirus1, Aichivirus A, cardiovirus, parechovirus A, astrovirus VA4, cosavirus-F, and bufavirus-3. Our results showed 71\% agreement $(k=0.445, P=0.000)$ between multiplex Real-Time PCR, which is used as a routine diagnostic test and metagenomics approach in the detection of viruses causing gastroenteritis in clinical samples.

Conclusion: Despite the difficulties in sample preparation and analysis process, we showed that metagenomics approach is a powerful and promising tool for the detection and characterisation of different viruses in clinical samples.

Keywords: Next-generation sequencing, Metagenomics approach, Viral gastroenteritis, Kuwait

\footnotetext{
* Correspondence: madi@hsc.edu.kw

Virology Unit, Department of Microbiology, Faculty of Medicine, Kuwait University, P.O.Box 24923, 13110 Safat, Kuwait
}

(c) The Author(s). 2020 Open Access This article is distributed under the terms of the Creative Commons Attribution 4.0 International License (http://creativecommons.org/licenses/by/4.0/), which permits unrestricted use, distribution, and reproduction in any medium, provided you give appropriate credit to the original author(s) and the source, provide a link to the Creative Commons license, and indicate if changes were made. The Creative Commons Public Domain Dedication waiver (http://creativecommons.org/publicdomain/zero/1.0/) applies to the data made available in this article, unless otherwise stated. 


\section{Background}

The traditional methods for virus discovery such as filtration, tissue culture, electron microscopy and serology were powerful techniques for the detection of viruses. However, due to their limitations, the traditional techniques were replaced by molecular techniques such as polymerase chain reaction (PCR) and DNA sequencing (Sanger method) [1]. Although these targetdependant molecular techniques had the credits in the discovery of many viruses, many new and novel human viruses are not yet revealed [2]. Therefore, innovative approaches that overcome the limitations of conventional methods for the detection of viruses in clinical samples are needed [3]. In 1998, the word metagenome was first used to define the collection of uncultivable microorganisms in a soil sample [4]. Now, this term is used to describe the characteristics of the recovered information from genomes directly from a sample [5-7]. Metagenomics approach based on NGS has been used to detect different infectious agents in different samples [8]. The first application of metagenomics study in virus discovery was the analysis of virus particles in soil samples from marine sites in San Diego [9]. Now, the metagenomics approach is used widely in different research areas, including marine ecological research, plant and agriculture, human genetics and diagnosis of human diseases [10]. Virologists were the first to use the metagenomics approach to detect viruses, causing different diseases in humans such as respiratory tract infections, acute flaccid paralysis in children, and gastroenteritis [8, 11, 12].

Gastroenteritis is the second leading cause of death among infants and children worldwide [13]. It is responsible for approximately three million deaths each year, causing high morbidity and mortality rate globally [14, 15]. Although at least 25 different bacteria and protozoa can cause diarrhoea, more than $75 \%$ of cases found to be caused by viruses [16]. Viruses that can cause gastroenteritis include rotavirus, norovirus, enteric adenovirus, human astrovirus, and Sapporo virus $[17,18]$. Currently, the diagnostic methods used to detect viruses in stool samples are sequence-dependent molecular amplification techniques such as PCR, which cannot identify a pool of viruses and completely new viruses in clinical samples. Therefore, a novel approach that is sequenceindependent such as viral metagenomics approach using NGS is desirable and should be developed for viral diagnosis and to overcome the unresolved cases of gastroenteritis.

\section{Materials and methods}

Eighty-four infants and children with signs and symptoms of gastroenteritis, including diarrhoea, vomiting, fever, and abdominal pain from January to December
2017 were enrolled in this study. The patients aged between 1 and 10 years old (median age $=2$ years old) who attended Al-Amiri and Mubarak Al-Kabeer Hospitals in Kuwait. Fresh stool samples were collected from the patients and stored in $-80^{\circ} \mathrm{C}$ for further processing. Patient's demographics were retrieved from the laboratory requests. Also, ten fresh stool samples were collected from healthy children aged between 1 and 5 years old (median age $=3.5$ years old). The collected samples from patients and healthy children were processed at the Virology Unit and Research Core Facility/OMICS Research Unit, Health Sciences Centre, Kuwait University, for the presence of viruses causing gastroenteritis by metagenomics approach using NGS and the commercial multiplex Real-Time PCR assay.

\section{Nucleic acids extraction}

The collected stool samples were re-suspended in phosphate buffer saline, incubated for $1 \mathrm{~h}$ at $4{ }^{\circ} \mathrm{C}$ and centrifuged at $6000 \mathrm{Xg}(5530 \mathrm{rpm})$ for $5 \mathrm{~min}$ at $4{ }^{\circ} \mathrm{C}$ to enrich the viruses. Total nucleic acids were extracted from stool samples using automated MagNA Pure LC system (Roche Diagnostics, Indianapolis, USA), according to the manufacturer's instructions.

\section{Next-generation sequencing and metagenomics analysis}

The extracted nucleic acids (RNA and DNA) were processed for metagenomics analysis using the Illumina MiSeq (San Diego, CA, USA) platform for NGS according to standard procedures [15]. Briefly, the genomic host DNA in the extracted nucleic acids was removed using Ambion DNA-free (Invitrogen, ThermoFisher Scientific, USA)) following the manufacturer's instructions. QuantiTect ${ }^{\oplus}$ Whole transcriptome, (Qiagen, Valencia, CA, USA) was used for the synthesis of singlestrand cDNA from the DNA free RNA primed by random hexamers and then amplified according to the manufacturer's instructions. Quantification of cDNA was performed using Qubit ${ }^{\mathrm{R}}$ Fluorometer and Qubit ${ }^{\mathrm{TM}}$ dsDNA BR Assay Kit (Invitrogen, California, USA) following the manufacturer's instructions and one ng of cDNA was used for library preparation. DNA libraries were prepared using Illumina TruSeq DNA Library Preparation Kit V2 (Illumina San Diego, CA, USA). The pooled DNA libraries were sequenced using the Illumina MiSeq instrument at Research Core Facility/OMICS Research Unit, Health Science Centre, Kuwait University, to generate 150 -bp paired-end reads.

\section{Bioinformatics}

After sequencing by Miseq sequencer, fastq sequence files were checked for quality using Fastqc (Andrews, 2014) and low quality ends, below 20 and above 240, were trimmed using FASTX-Toolkit (http://hannonlab. 
cshl.edu/fastx_toolkit/). The genome sequence of human, viruses, and bacteria was downloaded from NCBI (National Center for Biotechnology Information) RefSeq, and a custom database was created using build option in Kraken software. Each paired-end fastq file was mapped to the database using Kraken (Wood and Salzberg, 2014) to assign taxonomic labels to the sequences. For a detailed analysis of the reads, fastq files were also mapped to the database using BWA-MEM (Burrows-Wheeler Alignment mem option) (Li and Durbin, 2009) and sam files were obtained for the alignment and were filtered for MAPQ score 0. Samtools flagstat was used for the information about the percentage of reads aligned to each database (Li et al., 2009a). The sam files generated from the BWA program was analyzed by bbmap (https://jgi.doe.gov/data-and-tools/bbtools/) for detailed analysis. Raw reads data with high-quality reads were archived at NCBI (https://www.ncbi.nlm.nih.gov/) as sequence read archive (SRA) with BioProject accession number: PRJNA587350.

\section{Multiplex real-time PCR assay}

New nucleic acid extractions from each sample were prepared and used for multiplex Real-Time PCR. Fast Track Diagnostic Kit (Fast-Track Diagnostic, Luxemburg, Germany) was used to detect viruses causing AGE according to the manufacturer's instructions. The assay is a routine diagnostic test which is performed at the Virology Unit, Mubarak Al-Kabeer Hospital, Kuwait, for the detection of viruses that cause gastroenteritis including norovirus genotype 1 and 2; astrovirus; rotavirus; adenovirus; and sapovirus. All runs were performed using the LightCycler 480 instrument II (Roche Diagnostic, Mannheim, Germany).

\section{Statistical analysis}

The data were analysed using computer software "Statistical Package for Social Sciences", SPSS version 25.0 (IBM Corp, Armonk, NY). The descriptive statistics were presented as frequencies and percentages. Cohen's Kappa statistics $(k)$ was applied to find the agreement by both metagenomics and multiplex Real-Time PCR assays. Two-tailed probability value $P<0.05$ was considered statistically significant.

\section{Results}

\section{Characteristics of the study population}

Between January-December 2017, a total of 84 stool samples from infants and children were collected from two hospitals in Kuwait; Al-Amiri and Mubarak AlKabeer Hospitals. Among these patients, 59 (70.2\%) were males, and $25(29.7 \%)$ were females, $44(52.4 \%)$ of the patients were non-Kuwaiti, and 40 (47.6\%) were Kuwaiti. The median age of the patients was two years old. At the time of admission, the patients were complaining of different clinical presentations of gastroenteritis; $67.8 \%$ $(n=57)$ of the patients had diarrhoea, $13.0 \%(n=11)$ had bloody diarrhoea, 3.5\% $(n=3)$ had fever, $1.1 \%(n=1)$ had vomiting, and $14.2 \%(n=12)$ had other symptoms such as abdomen pain, sepsis, and weight loss. As a control measure, ten fresh stool samples from healthy children were included in this study, 3 (30\%) of the children were females, and 7 (70\%) were males. The children aged 1-5 years old (median age $=3.5$ years).

\section{Virus detection by metagenomics approach}

From the total of 94 stool samples collected from patients with gastroenteritis and healthy individuals, cDNA was obtained to perform whole-genome sequencing using Illumina Miseq sequencer for the detection of RNA and DNA viruses causing gastroenteritis. Sequencing of cDNA libraries pooled from all samples generated an average of 280,768 reads (range; 404-1,001,170) after quality filtering and trimming. On an average; $29 \%$ (range; $0.04-88.35 \%$ ) of the reads were originated from host (human) genome; $27 \%$ (range; $2.25-70.03 \%$ ) of the reads belonged to bacteria genome, 5\% (range; $0.02-$ $25.02 \%$ ) of reads derived from viruses; and the remaining reads $(39 \%)$ were obtained from other organisms that could not be matched to any of the known in the database (Fig. 1).

Viral sequences identified from metagenomic sequencing approach after alignment using Kraken software were originated from human, animal and plantassociated viruses. Human viruses causing gastroenteritis were found in 43 out of $84(51.1 \%)$ patients tested, and they were as follow (Fig. 2): human adenovirus (10; 23.2\%), mixed infection of human adenovirus and other viruses $(9 ; 20.9 \%)$, rotavirus A $(7 ; 16.2 \%)$, norovirus GII (5; 11.6\%), enteroviruses (4; 9.3\%). Moreover, metagenomics sequencing approach exhibited its feasibility to detect the newly discovered viruses causing gastroenteritis despite the low number of reads obtained, and these

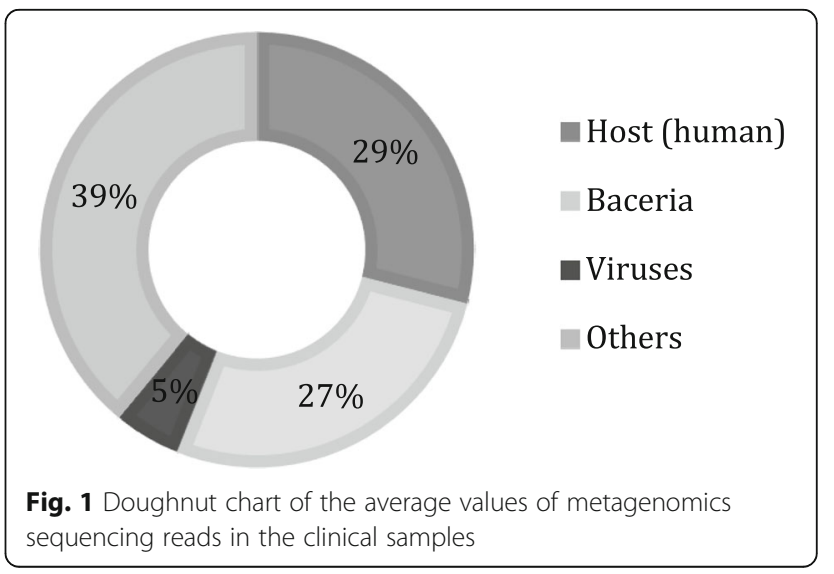




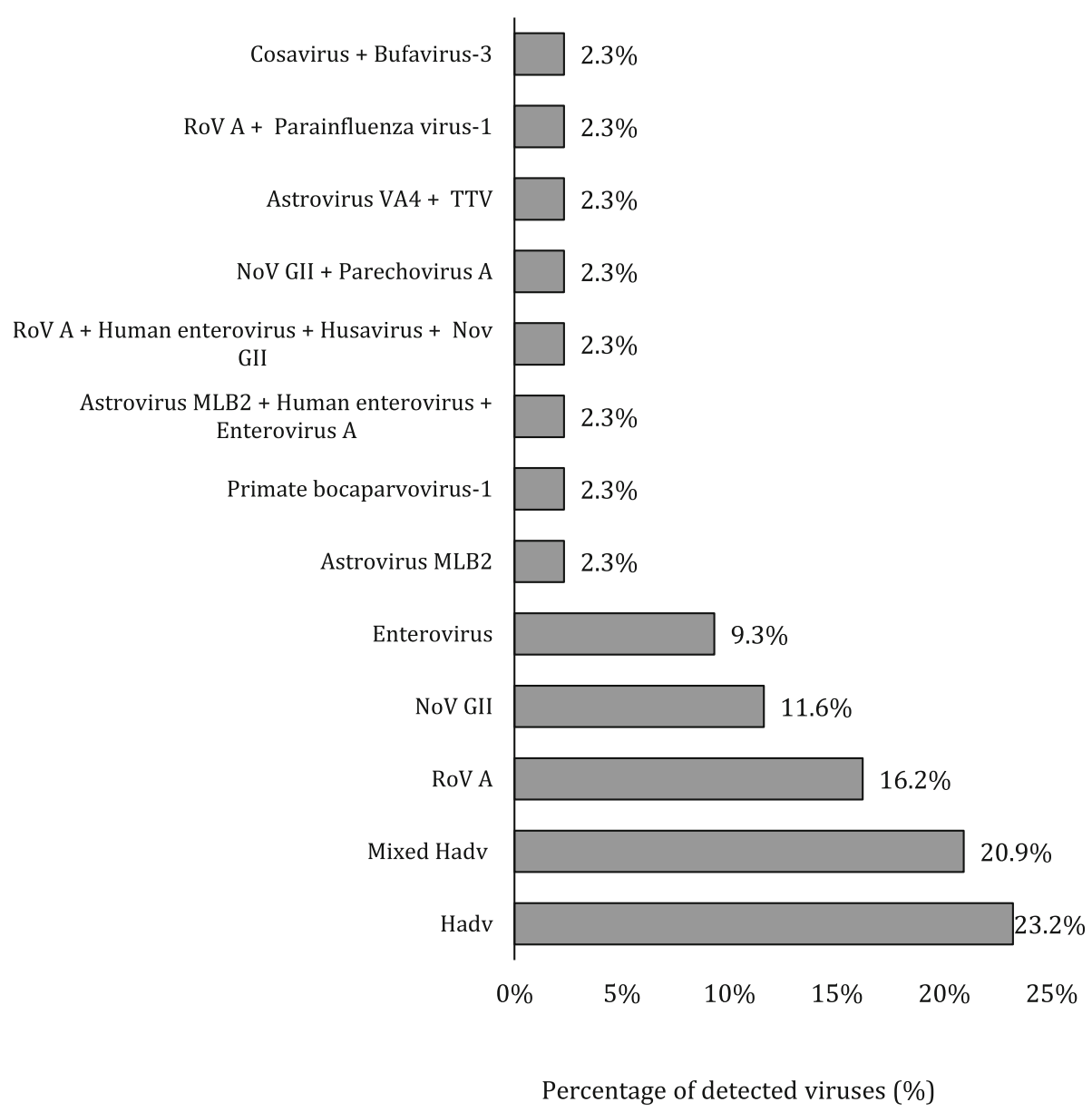

Fig. 2 Clustered Bar chart of the percentage of patients positive for viruses causing gastroenteritis and non-gastroenteritis viruses detected by metagenomics sequencing approach $(n=84)$. RoV, Rotavirus; NoV GIl, Norovirus Gll; Hadv, Human adenovirus; TTV, Torque teno virus

viruses were as follow: astrovirus MLB2 was found in one $(2.3 \%)$ patient; primate bocaparvovirus-1 was found in one (2.3\%) patient; mixed infection of primate bocavirus-1 and adenovirus was found in one $(2.3 \%)$ patient; mixed infection of astrovirus MLB2, human enterovirus, and enterovirus A was found in one (2.3\%) patient. Furthermore, other new viruses were found as a mixed infection with other viruses, and each combination was detected in one (2.3\%) patient (Fig. 2, Table 1): Aichi virus; cardiovirus (saffold); parechovirus A; astrovirus VA4; cosavirus $\mathrm{F}$; and bufavirus-3. In addition to viruses causing gastroenteritis, non-gastroenteritis viruses were detected by metagenomics analysis, and they presented as mixed infection; husavirus was detected in one $(2.3 \%)$ patients, torque teno virus was detected in one $(2.3 \%)$ patients, and parainfluenza virus-1 was detected in one $(2.3 \%)$ patient. The metagenomics analysis revealed the presence of different genotypes of viruses such as different types of human adenovirus (A-G), enterovirus (A-D), and norovirus GII in the samples (Table 1). Along with patients with AGE, stool samples from ten healthy children were tested; three were positive for gastroenteritis viruses; one child had human adenovirus $\mathrm{C}$, the second had rotavirus $\mathrm{A}$, and the third had astrovirus MLB2 (Table 1).

The number of viral reads obtained from metagenomics approach raged from 1 to 1272, and the highest number of reads was for Astrovirus MLB2. The highquality reads were archived at NCBI as SRA with accession numbers presented in the Additional file 1.

\section{Virus detection by multiplex real-time PCR}

The 84 stool samples from patients with symptoms of gastroenteritis were also tested for the presence of viruses by multiplex Real-Time PCR assay. The results demonstrated that $51(60.7 \%)$ of the patients were positive for viruses causing gastroenteritis and 33 (39.2\%) of the patients were negative. Amongst the positive patients, 14 patients $(27.4 \%)$ had mixed infection of rotavirus, and human adenovirus, ten patients (19.6\%) had rotavirus, nine patients (17.6\%) had human adenovirus, four patients $(7.8 \%)$ had a norovirus GII, and one patient 
Table 1 Study population characteristics and results of Multiplex Real-time PCR and Metagenomics approach $(n=94)$

\begin{tabular}{|c|c|c|c|c|c|c|}
\hline Sample No. & Age & Gender & Metagenomics sequencing results & No. of Reads & Multiplex Real-Time PCR results & CT value \\
\hline 1 & $1 \mathrm{yr}$ & $\mathrm{F}$ & Rotavirus A & 1 & Rotavirus & 26.48 \\
\hline 2 & $2 \mathrm{yr}$ & $\mathrm{F}$ & - & & - & \\
\hline 3 & $3 \mathrm{yr}$ & M & - & & - & \\
\hline 4 & $2 \mathrm{mo}$ & M & - & & - & \\
\hline 5 & $2 \mathrm{mo}$ & M & - & & - & \\
\hline 6 & $6 \mathrm{yr}$ & M & Human adenovirus $\mathrm{E}$ & 4 & - & \\
\hline 7 & $2 \mathrm{yr}$ & $\mathrm{F}$ & - & & - & \\
\hline 8 & $2 \mathrm{yr}$ & M & Astrovirus MLB2 & 4 & Human adenovirus & 25.73 \\
\hline 9 & $1 \mathrm{mo}$ & M & - & & - & \\
\hline 10 & $2 \mathrm{yr}$ & M & - & & - & \\
\hline 11 & $2 \mathrm{yr}$ & M & Human adenovirus $\mathrm{E}$ & 1 & Human adenovirus & 31.99 \\
\hline \multirow[t]{2}{*}{12} & $1 \mathrm{yr}$ & M & - & & Rotavirus & 14.53 \\
\hline & & & & & Human adenovirus & 28.68 \\
\hline 13 & $3 \mathrm{yr}$ & M & - & & - & \\
\hline 14 & $3 \mathrm{yr}$ & M & - & & - & \\
\hline 15 & $7 \mathrm{mo}$ & M & - & & Norovirus Gll & 16.33 \\
\hline 16 & $3 \mathrm{yr}$ & M & - & & - & \\
\hline \multirow[t]{4}{*}{17} & $1 \mathrm{yr}$ & M & - & & Rotavirus & 18.61 \\
\hline & & & & & Human adenovirus & 30.20 \\
\hline & & & & & Sapporo virus & 33.30 \\
\hline & & & & & Norovirus GII & 28.57 \\
\hline \multirow[t]{3}{*}{18} & $1 \mathrm{yr}$ & M & Human adenovirus $C$ & 12 & Human adenovirus & 23.96 \\
\hline & & & Human adenovirus $\mathrm{E}$ & 2 & Norovirus GII & 17.33 \\
\hline & & & Norovirus Gll & 11 & & \\
\hline \multirow[t]{3}{*}{19} & $4 \mathrm{yr}$ & $\mathrm{F}$ & Enterovirus C & 587 & - & \\
\hline & & & Enterovirus B & 452 & & \\
\hline & & & Enterovirus D & 1 & & \\
\hline \multirow[t]{2}{*}{20} & $3 \mathrm{yr}$ & M & - & & Rotavirus & 25.90 \\
\hline & & & & & Human adenovirus & 20.05 \\
\hline \multirow[t]{2}{*}{21} & $2 \mathrm{yr}$ & $\mathrm{F}$ & Norovirus Gll & 2 & Rotavirus & 31.62 \\
\hline & & & Human adenovirus $C$ & 1 & Human adenovirus & 33.00 \\
\hline 22 & $1 \mathrm{yr}$ & M & Primate bocaparvovirus-1 & 1 & Rotavirus & 32.65 \\
\hline 23 & $1 \mathrm{yr}$ & M & - & & - & \\
\hline 24 & $4 \mathrm{yr}$ & M & - & & - & \\
\hline 25 & $1 \mathrm{yr}$ & M & Human adenovirus $C$ & 1 & Rotavirus & 26.36 \\
\hline 26 & $2 \mathrm{mo}$ & $\mathrm{F}$ & - & & - & \\
\hline 27 & $3 \mathrm{mo}$ & M & Human enterovirus & 2 & - & \\
\hline 28 & $3 \mathrm{mo}$ & M & - & & - & \\
\hline 29 & $1 \mathrm{yr}$ & M & Enterovirus B & 3 & - & \\
\hline Sample No. & Age & Gender & Metagenomics sequencing results & No. of Reads & Multiplex Real-Time PCR results & CT value \\
\hline \multirow[t]{3}{*}{30} & $4 \mathrm{mo}$ & M & Human adenovirus $F$ & 744 & Human adenovirus & 12.31 \\
\hline & & & Human adenovirus $C$ & 47 & & \\
\hline & & & Human adenovirus $B$ & 9 & & \\
\hline 31 & $3 \mathrm{yr}$ & $F$ & - & & - & \\
\hline
\end{tabular}


Table 1 Study population characteristics and results of Multiplex Real-time PCR and Metagenomics approach ( $n=94)$ (Continued)

\begin{tabular}{|c|c|c|c|c|c|c|}
\hline Sample No. & Age & Gender & Metagenomics sequencing results & No. of Reads & Multiplex Real-Time PCR results & CT value \\
\hline \multirow[t]{5}{*}{32} & $4 \mathrm{yr}$ & M & Human adenovirus $F$ & 550 & Human adenovirus & 10.62 \\
\hline & & & Human adenovirus $B$ & 12 & & \\
\hline & & & Human adenovirus $\mathrm{E}$ & 4 & & \\
\hline & & & Human adenovirus $\mathrm{C}$ & 4 & & \\
\hline & & & Human adenovirus D & 4 & & \\
\hline \multirow[t]{3}{*}{33} & $2 \mathrm{yr}$ & M & Rotavirus A & 41 & Rotavirus & 16.40 \\
\hline & & & Human adenovirus $\mathrm{C}$ & & Human adenovirus & 26.55 \\
\hline & & & & 1 & & \\
\hline \multirow[t]{3}{*}{34} & $2 \mathrm{yr}$ & M & Astrovirus MLB2 & 1272 & Human adenovirus & 32.47 \\
\hline & & & Human enterovirus & 1 & Norovirus GII & 24.99 \\
\hline & & & Enterovirus A & 1 & & \\
\hline \multirow[t]{2}{*}{35} & $4 \mathrm{yr}$ & $\mathrm{F}$ & - & & Rotavirus & 30.78 \\
\hline & & & & & Human adenovirus & 27.83 \\
\hline 36 & $2 \mathrm{yr}$ & M & Human adenovirus $B$ & 1 & Human adenovirus & 21.38 \\
\hline 37 & $5 \mathrm{yr}$ & $\mathrm{F}$ & Human adenovirus F & 2 & - & \\
\hline 38 & $4 \mathrm{yr}$ & M & - & & - & \\
\hline \multirow[t]{4}{*}{39} & $1 \mathrm{yr}$ & M & Rotavirus A & 5 & Rotavirus & 14.65 \\
\hline & & & Human enterovirus & 1 & Human adenovirus & 24.82 \\
\hline & & & Husavirus & 2 & & \\
\hline & & & Norovirus GII & 1 & & \\
\hline \multirow[t]{2}{*}{40} & $8 \mathrm{mo}$ & M & Human adenovirus F & 436 & Human adenovirus & 12.48 \\
\hline & & & Human adenovirus $C$ & 9 & & \\
\hline \multirow[t]{2}{*}{41} & $4 \mathrm{yr}$ & M & Human adenovirus B & 1 & Rotavirus & 32.64 \\
\hline & & & Husavirus & 1 & Human adenovirus & 19.34 \\
\hline 42 & $4 \mathrm{yr}$ & M & - & & - & \\
\hline \multirow[t]{2}{*}{43} & $7 \mathrm{mo}$ & $\mathrm{F}$ & - & & Rotavirus & 14.83 \\
\hline & & & & & Human adenovirus & 32.30 \\
\hline \multirow[t]{2}{*}{44} & $2 \mathrm{yr}$ & M & Rotavirus A & 3 & Rotavirus & 16.99 \\
\hline & & & Human adenovirus $B$ & 1 & Human adenovirus & $32 . .82$ \\
\hline \multirow[t]{4}{*}{45} & $2 \mathrm{yr}$ & $\mathrm{F}$ & Cardiovirus (saffold) & 8 & Human astrovirus & 32.51 \\
\hline & & & Human adenovirus $\mathrm{E}$ & 1 & Human adenovirus & 32.88 \\
\hline & & & Torque teno virus-3 & 4 & & \\
\hline & & & Torque teno virus-19 & 1 & & \\
\hline 46 & $4 \mathrm{yr}$ & M & - & & Human adenovirus & 26.44 \\
\hline \multirow[t]{2}{*}{47} & $2 \mathrm{yr}$ & $\mathrm{F}$ & - & & Rotavirus & 19.81 \\
\hline & & & & & Human adenovirus & 28.67 \\
\hline Sample No. & Age & Gender & Metagenomics sequencing results & No. of Reads & Multiplex Real-Time PCR results & CT value \\
\hline 48 & $2 \mathrm{yr}$ & $\mathrm{F}$ & Rotavirus A & 105 & Rotavirus & 22.31 \\
\hline \multirow[t]{2}{*}{49} & $3 \mathrm{yr}$ & $\mathrm{F}$ & - & & Rotavirus & 29.60 \\
\hline & & & & & Human adenovirus & 29.52 \\
\hline 50 & $1 \mathrm{mo}$ & M & - & & - & \\
\hline 51 & $4 \mathrm{mo}$ & M & - & & - & \\
\hline \multirow[t]{2}{*}{52} & $2 \mathrm{yr}$ & $\mathrm{F}$ & Rotavirus A & 2 & Rotavirus & 16.72 \\
\hline & & & & & Human adenovirus & 29.55 \\
\hline
\end{tabular}


Table 1 Study population characteristics and results of Multiplex Real-time PCR and Metagenomics approach ( $n=94)$ (Continued)

\begin{tabular}{|c|c|c|c|c|c|c|}
\hline Sample No. & Age & Gender & Metagenomics sequencing results & No. of Reads & Multiplex Real-Time PCR results & $\mathrm{CT}$ value \\
\hline 53 & $1 \mathrm{yr}$ & M & - & & - & \\
\hline 54 & $1 \mathrm{yr}$ & M & - & & Rotavirus & 32.55 \\
\hline \multirow[t]{2}{*}{55} & $5 \mathrm{yr}$ & M & Rotavirus A & 2 & Rotavirus & 12.85 \\
\hline & & & & & Human adenovirus & 32.62 \\
\hline \multirow[t]{2}{*}{56} & $1 \mathrm{yr}$ & $\mathrm{F}$ & - & & Rotavirus & 21.22 \\
\hline & & & & & Human adenovirus & 32.30 \\
\hline 57 & $10 \mathrm{mo}$ & M & Rotavirus A & 40 & Rotavirus & 17.84 \\
\hline 58 & $2 \mathrm{mo}$ & $\mathrm{F}$ & Human adenovirus $\mathrm{A}$ & 1 & Rotavirus & 32.22 \\
\hline \multirow[t]{3}{*}{59} & $1 \mathrm{yr}$ & M & Norovirus GII & 10 & Norovirus Gll & 15.87 \\
\hline & & & Parechovirus A & 1 & Sapporo virus & 18.42 \\
\hline & & & & & Human adenovirus & 32.51 \\
\hline \multirow[t]{3}{*}{60} & $1 \mathrm{yr}$ & M & Rotavirus A & 4 & Rotavirus & 16.78 \\
\hline & & & Human adenovirus $B$ & 1 & Human adenovirus & 26.70 \\
\hline & & & Aichi virus $A$ & 1 & Norovirus GII & 27.57 \\
\hline \multirow[t]{4}{*}{61} & $3 \mathrm{yr}$ & M & Primate bocaparvovirus 1 & 6 & Rotavirus & 16.34 \\
\hline & & & Human adenovirus $B$ & 1 & Human adenovirus & 29.83 \\
\hline & & & Human adenovirus $\mathrm{G}$ & 1 & Norovirus GII & 28.49 \\
\hline & & & Norovirus GII & 1 & & \\
\hline \multirow[t]{2}{*}{62} & $8 \mathrm{mo}$ & M & - & & Human adenovirus & 32.87 \\
\hline & & & & & Norovirus GII & 31.84 \\
\hline \multirow[t]{3}{*}{63} & $3 \mathrm{yr}$ & M & - & - & Rotavirus & 20.27 \\
\hline & & & & & Human adenovirus & 30.71 \\
\hline & & & & & Norovirus GII & 28.94 \\
\hline 64 & $1 \mathrm{yr}$ & M & Rotavirus A & 13 & Rotavirus & 18.31 \\
\hline \multirow[t]{2}{*}{65} & $3 \mathrm{yr}$ & $\mathrm{F}$ & Astrovirus VA4 & 2 & Human adenovirus & 32.63 \\
\hline & & & Torque teno virus & 1 & Norovirus Gl & 30.00 \\
\hline \multirow[t]{2}{*}{66} & $2 \mathrm{yr}$ & M & Rotavirus A & 5 & Rotavirus & 20.58 \\
\hline & & & Parainfluenza virus 1 & 10 & & \\
\hline 67 & $4 \mathrm{yr}$ & M & - & & - & \\
\hline 68 & $7 \mathrm{yr}$ & $\mathrm{F}$ & Human adenovirus $B$ & 5 & - & \\
\hline 69 & $1 \mathrm{mo}$ & $\mathrm{F}$ & - & - & - & \\
\hline 70 & $3 \mathrm{mo}$ & M & - & - & - & \\
\hline 71 & $3 \mathrm{yr}$ & M & - & - & - & \\
\hline \multirow[t]{2}{*}{72} & $6 y \mathrm{r}$ & M & Cosavirus F & 1 & Human adenovirus & 31.84 \\
\hline & & & Bufavirus-3 & 1 & & \\
\hline 73 & $4 \mathrm{yr}$ & $\mathrm{F}$ & Norovirus GII & 1 & - & \\
\hline Sample No. & Age & Gender & Metagenomics sequencing results & No. of Reads & Multiplex Real-Time PCR results & CT value \\
\hline \multirow[t]{3}{*}{74} & $1 \mathrm{yr}$ & M & Rotavirus A & 18 & Rotavirus & 14.76 \\
\hline & & & & & Human adenovirus & 29.54 \\
\hline & & & & & Sapporo virus & 27.25 \\
\hline 75 & $3 \mathrm{mo}$ & M & - & - & - & \\
\hline 76 & $1 \mathrm{mo}$ & M & - & & Human adenovirus & 33.00 \\
\hline 77 & $4 \mathrm{mo}$ & M & Enterovirus C & 11 & - & \\
\hline 78 & $1 \mathrm{yr}$ & $\mathrm{F}$ & - & - & Human astrovirus & 31.73 \\
\hline
\end{tabular}


Table 1 Study population characteristics and results of Multiplex Real-time PCR and Metagenomics approach ( $n=94)$ (Continued)

\begin{tabular}{|c|c|c|c|c|c|c|}
\hline Sample No. & Age & Gender & Metagenomics sequencing results & No. of Reads & Multiplex Real-Time PCR results & CT value \\
\hline 79 & $5 \mathrm{mo}$ & $\mathrm{F}$ & Norovirus Gll & 3 & Norovirus Gll & 16.96 \\
\hline \multirow[t]{2}{*}{80} & $6 \mathrm{mo}$ & M & Norovirus Gll & 621 & Norovirus Gll & 13.57 \\
\hline & & & & & Human adenovirus & 32.77 \\
\hline \multirow[t]{3}{*}{81} & $2 \mathrm{yr}$ & $\mathrm{F}$ & Human adenovirus $C$ & 159 & Rotavirus & 30.97 \\
\hline & & & Norovirus Gll & 26 & Human adenovirus & 23.34 \\
\hline & & & & & Norovirus Gll & 16.51 \\
\hline 82 & $2 \mathrm{yr}$ & $\mathrm{F}$ & Norovirus Gll & 5 & Norovirus Gll & 19.25 \\
\hline 83 & $2 \mathrm{yr}$ & M & Norovirus Gll & 33 & Norovirus Gll & 16.88 \\
\hline 84 & $5 \mathrm{yr}$ & M & - & - & Rotavirus & 19.36 \\
\hline 85 & $2 \mathrm{yr}$ & $\mathrm{F}$ & - & - & - & \\
\hline 86 & $1 \mathrm{yr}$ & M & - & - & - & \\
\hline 87 & $3 \mathrm{yr}$ & $\mathrm{F}$ & - & - & - & \\
\hline 88 & $5 \mathrm{yr}$ & M & Husavirus & 1 & - & \\
\hline 89 & $4 \mathrm{yr}$ & M & - & - & - & \\
\hline 90 & $2 \mathrm{yr}$ & M & - & - & - & \\
\hline \multirow[t]{2}{*}{91} & $4 \mathrm{yr}$ & M & Human adenovirus $C$ & 1 & Rotavirus & 16.52 \\
\hline & & & & & Human adenovirus & 31.35 \\
\hline 92 & $4 \mathrm{yr}$ & $\mathrm{F}$ & - & - & - & \\
\hline 93 & $4 \mathrm{yr}$ & M & Rotavirus A & 3 & Rotavirus & 16.44 \\
\hline 94 & $2 \mathrm{yr}$ & M & Astrovirus MLB2 & 1 & - & \\
\hline
\end{tabular}

(1.9\%) had human astrovirus. Also, other patients had mixed viral infection, but in low percentage (Fig. 3). On the other hand, out of the ten healthy children tested, two were positive for gastroenteritis viruses; one child had rotavirus, and the other one had a mixed infection of rotavirus and human adenovirus. The threshold cycle value $\left(C_{T}\right)$ for each detected virus is shown in Table 1.

\section{Comparison between multiplex real-time PCR and metagenomics approach}

To evaluate the capability of the metagenomics approach to detect viruses causing gastroenteritis, the results of multiplex Real-Time PCR and metagenomics sequencing approaches were compared (Table 1). Of the 94 stool samples, $53(56 \%)$ samples were positive for viruses causing gastroenteritis by Real-Time multiplex PCR and 41 (44\%) samples were negative. However, using metagenomic sequencing approach, 46 (49\%) samples were positive for viruses causing gastroenteritis, and 48 (51\%) samples were negative. Generally, 30 (32\%) samples were detected as positive for the same viruses, and 37 (39.3\%) as negative by both methods, resulting in an absolute agreement on 67 (71\%) samples. Regarding the negative samples, it is important to mention that the positive metagenomics samples other than those detected by Real-Time multiplex PCR were considered as negative. By applying the Cohen's Kappa statistics for a measure of agreement, the result gave moderate agreement between the two methods ( $\mathrm{k}=0.445, P=0.000)$.

\section{Discussion}

In this study, we demonstrated the potential of metagenomics approach using high-throughput NGS method to reveal viruses present in stool samples from AGE cases in infants and children in Kuwait between JanuaryDecember 2017. This study is the first of its kind in Kuwait to perform metagenomics analysis using NGS to detect various viruses causing gastroenteritis in stool samples from infants and children with signs and symptoms of gastroenteritis. Stool samples from 94 patients with gastroenteritis and healthy children were first analysed for the presence of viruses by metagenomic approach using NGS. The results showed that cDNA libraries generated an average of 280,768 reads of 150-bp paired-end reads. Among the total reads, 29\% of the reads were originated from the host (human), $27 \%$ of the reads were obtained from the bacterial genome, while only $5 \%$ of reads were derived from viruses. In comparison to our results, Yang and colleagues identified a higher average (91.6\%) of host (human) genome reads, and $61.5 \%$ were from the bacterial genome in the clinical samples [19]. However, Madi and colleagues identified an average of $64 \%$ of the host (human) genome reads in respiratory samples [20]. In our study, the viral reads 


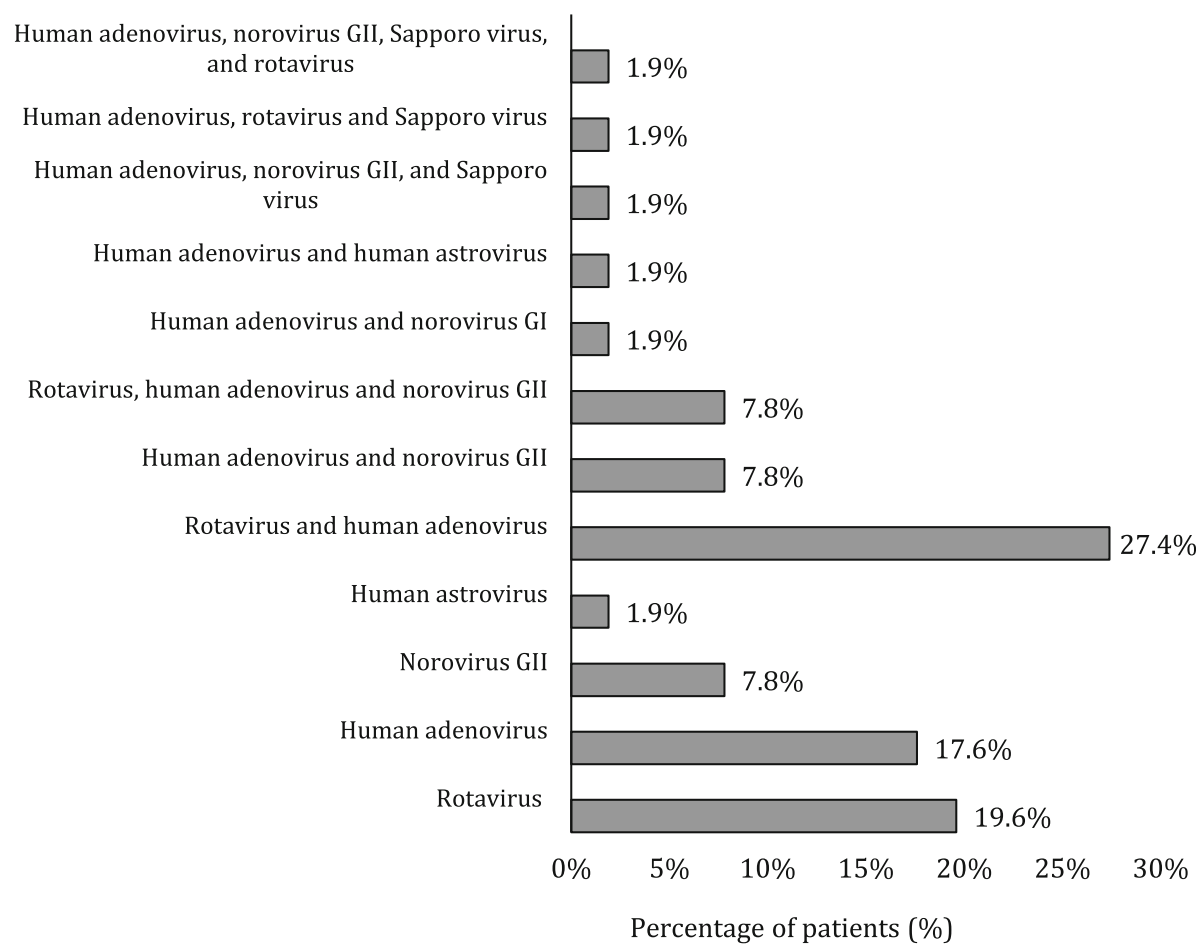

Fig. 3 Clustered Bar chart of the percentage of patients positive for viruses causing gastroenteritis detected by multiplex RT-PCR assay $(n=51)$

were higher in comparison to other studies; Yang and colleagues identified only $3.1 \%$ of viral reads [19], while Madi and coworkers identified a lower average of viral reads $(2 \%)$ [20]. On the other hand, other studies of viral metagenomics in stool samples have recorded better viral reads; 76\% [21], 35.6\% [22], and 23\% [23]. Probably, the two-steps of DNase treatment of the samples which was performed in this study have resulted in the enrichment of the viral particles and reduced the host genome.

After the assembly of the contigs generated by NGS, the results showed that 43 out of 85 (51\%) stool samples collected from infants and children with AGE were positive for viruses known to cause gastroenteritis. Human adenovirus was the predominant virus detected in stool samples (23.2\%), and the combined infection of human adenovirus and other viruses was the second most prevalent infection $(20.9 \%)$. However, rotavirus A was the third predominant virus detected in stool samples (16.2\%) followed by norovirus GII (11.6\%). By a study in southern Brazil to investigate viruses causing gastroenteritis in hospitalised pediatric patients, the results showed that out of 225 fecal samples tested, human adenovirus was the predominant virus (16\%), while $8 \%$ of the samples were positive for norovirus, and $6 \%$ were positive for rotavirus [24]. Additionally, many studies have shown that human enteric adenovirus types 40 and 41 (HAdV-40, AHdV-41) are an important cause of gastroenteritis [25-28]. In contrary to our study, updated estimates on diarrhoea-related childhood revealed that rotavirus is the leading cause of diarrhoea among children worldwide [29-32]. A previous study in Kuwait has investigated the prevalence of viruses causing gastroenteritis in stool samples from children aged up to five years with acute gastroenteritis using an electron microscope and enzyme immunoassay. The results showed that rotavirus was the primary (40\%) virus causing diarrhoea among children in Kuwait [33, 34]. Concerning norovirus, other studies have also demonstrated that norovirus GII is the predominant genogroup known to cause gastroenteritis in children [35-38].

One of the features of the metagenomic approach is its ability to determine different genogroups and subtypes of viruses. In this study, different genotypes of adenovirus (A-G) and enterovirus (A-D) were detected. Furthermore, the approach detected norovirus GII as the main genogroup presented in the samples.

The results of the metagenomic analysis in this study have demonstrated that mix viral infection is a common phenomenon in patients with gastroenteritis (Fig. 2). In our study, 15 out of 43 (35\%) stool samples from patients with gastroenteritis had mixed infection with one or more enteric viruses. Adenoviruses were detected as co-infection viruses in $20.9 \%(9 / 43)$ of the positive samples. According to several studies conducted in Korea, Japan, Albania, and Venezuela, mixed infections of enteric and non-enteric adenoviruses are common and 
might play a role in acute gastroenteritis [39-43]. The clinical importance of mixed viral infection is an unresolved question. However, mixed viral infections have biological and epidemiological implications. Viruses in mixed infections may interact synergistically or antagonistically altering the concentration of either or both viruses and accordingly affecting the outcome of the disease. We speculate that some viruses which are causing gastroenteritis to depend on other viruses for their pathogenicity. However, this concept requires further investigations.

The most interesting clinical finding for this study was the detection of many newly discovered viruses, which might be associated with gastroenteritis, and they were as follow; primate bocaparvovirus-1, astrovirus MLB2, astrovirus VA4, cardiovirus (saffold), parechovirus A, Aichi virus $\mathrm{A}$, cosavirus $\mathrm{F}$, and bufavirus-3. It is noteworthy that this study is the first study in Kuwait to detect these novel viruses in stool samples using a metagenomics approach.

Gastroenteritis samples were analysed further using multiplex Real-Time PCR using FTD kit as a comparison and reference test for the presence of viruses causing gastroenteritis in stool samples from patients and healthy children. In our study, the results showed that $60.7 \%$ of patients were positive for viruses causing gastroenteritis disease. Of the positive patients, $53 \%$ had mixed viral infections. Mixed infection of adenovirus and rotavirus was the predominant (27.4\%). A similar percentage of mixed infection of human adenovirus and rotavirus $(27.2 \%)$ was reported in a study conducted in Albania to assess the occurrence of human adenovirus in children with acute gastroenteritis symptoms [42]. In our study, rotavirus was the most predominant virus detected by multiplex Real-Time PCR as a single infection (19.6\%). However, this percentage is lower than the percentage of rotavirus recorded previously in Kuwait [33, 34]. We speculate that the reduced incidence of rotavirus among children is due to the implementation of rotavirus vaccine in Kuwait.

The comparison of the metagenomic sequencing data and that of multiplex RT-PCR revealed an absolute moderate agreement of $71 \%(\mathrm{k}=0.445)$. The divergence between the results obtained by multiplex Real-Time PCR and metagenomics approach could be explained by the fact that multiplex Real-Time PCR is a standardised technique that is routinely used for the detection of the commonly known viruses associated with gastroenteritis. On the contrary, the metagenomics approach is a newly introduced technology in Kuwait and requires further standardisations and validations in order to use it as a routine diagnostic test. The question is how to intercept metagenomics analysis results by NGS in term of what is clinically relevant for patients requires further investigations. Although metagenomics did not detect all multiplex Real-Time PCR positive samples, it did provide several advantages over the multiplex Real-Time PCR assay. For instance, the metagenomics approach detected several known and newly discovered viruses among children with gastroenteritis for the first time in Kuwait that could not be identified by the multiplex Real-Time PCR method. Moreover, the metagenomic approach had the advantage to detect different genogroup of viruses, for example, adenovirus, enterovirus and norovirus genotypes. Also, unlike multiplex Real-Time PCR, the metagenomic approach can detect completely new viruses.

This study had many limitations - first, the small samples size of both patients with AGE and healthy children. Second, low total reads and viral reads obtained by NGS, which can be improved by enrichment of virus content in the samples.

\section{Conclusion}

In conclusion, the metagenomic-sequencing approach was successfully implemented to detect viruses in infants and children with gastroenteritis in Kuwait. We showed that metagenomics analysis holds promise as a diagnostics tool, where multiplex Real-Time PCR could not identify many viruses known to cause gastroenteritis but were detected by metagenomics approach. Although metagenomics has provided a powerful tool for detecting the newly discovered viruses that cause gastroenteritis, the detection of these viruses is not sufficient to prove causality. Based on these findings, we cannot rule out these viruses as the cause of acute gastroenteritis in infants and children. Therefore, further studies in the immediate future with a larger sample size of healthy controls and causes of AGE are needed to evaluate their clinical significance.

To become a routine diagnostic tool, the approach requires further improvement in sample preparation, validation of pipelines for reads sorting and taxonomic assignation, lower the prices of the machine and reagents, and standardisation. These developments will expedite the feasibility of metagenomics approach and allow its implementation in every diagnostic laboratory.

\section{Supplementary information}

Supplementary information accompanies this paper at https://doi.org/10. 1186/s12985-020-1287-5.

Additional file 1. Accession numbers of the highest quality reads at NCBI as SRA

Abbreviations

AGE: Acute gastroenteritis; FTD: Fast track diagnostic; NGS: Next-generation sequencing; PCR: Polymerase chain reaction 


\section{Acknowledgements}

This study was gratefully supported by the College of Graduate Studies and Research Sector (Project Number: YM10/17). Special thanks to Research Core Facility and OMICS Research Unit for their support and help in using the facilities provided in the Unit. We are also grateful to Mr. Mohammed Khan for his outstanding help in the bioinformatics analysis of the data.

\section{Authors' contributions}

HA, NM, WA designed the study. HA was responsible for collecting clinical samples, conducting the tests and analysing the data. HA drafted the manuscript. NM and WA revised the manuscript. WA supervised overall work. All authors read and approved the final manuscript.

\section{Funding}

This project was funded by College of Graduate Studies and Research Sector, Kuwait University. Project Number YM10/17.

\section{Availability of data and materials}

All relevant data are within the paper.

\section{Ethics approval and consent to participate}

The study was approved by The Ethics Committee of Faculty of Medicine, Kuwait University.

\section{Consent for publication}

Not applicable.

\section{Competing interests}

All co-authors declare that they have no conflict of interests.

Received: 20 October 2019 Accepted: 20 January 2020

Published online: 30 January 2020

\section{References}

1. Wessels E, Rusman LG, van Bussel MJAWM, Claas ECJ. Added value of multiplex Luminex gastrointestinal pathogen panel (xTAG(R) GPP) testing in the diagnosis of infectious gastroenteritis. Clin Microbiol Infect. 2014;20:0182-7.

2. Anthony SJ, Epstein JH, Murray KA, Navarrete-Macias I, Zambrana-Torrelio CM, Solovyov A, et al. A strategy to estimate unknown viral diversity in mammals. MBio. 2013;4:e00598-13.

3. Denno DM, Klein EJ, Young VB, Fox JG, Wang D, Tarr PI. Explaining unexplained diarrhea and associating risks and infections. Anim Health Res Rev. 2007:8:69-80.

4. Handelsman J, Rondon MR, Brady SF, Clardy J, Goodman RM. Molecular biological access to the chemistry of unknown soil microbes: a new frontier for natural products. Chem Biol. 1998:5:R245-9 Available from: http://www. ncbi.nlm.nih.gov/pubmed/9818143 [cited 2015 Jan 5].

5. Handelsman J. Metagenomics: application of genomics to uncultured microorganisms. Microbiol Mol Biol Rev. 2004;68:669-85.

6. Radford AD, Chapman D, Dixon L, Chantrey J, Darby AC, Hall N. Application of next-generation sequencing technologies in virology. J Gen Virol. 2012; 93:1853-68 Available from: http://vir.sgmjournals.org/content/93/Pt_9/ 1853[cited 2014 Nov 16]

7. Garza DR, Dutilh BE. From cultured to uncultured genome sequences: metagenomics and modeling microbial ecosystems. Cell Mol Life Sci. 2015; 72:4287-308.

8. Pallen MJ. Diagnostic metagenomics: potential applications to bacterial, viral and parasitic infections. Parasitology. 2014;141:1856-62 Available from: http://www.pubmedcentral.nih.gov/articlerender.fcgi?artid=4255322\&tool= pmcentrez\&rendertype=abstract [cited 2015 Mar 15].

9. Breitbart M, Salamon P, Andresen B, Mahaffy JM, Segall AM, Mead D, et al. Genomic analysis of uncultured marine viral communities. Proc Natl Acad Sci U S A 2002;99:14250-14255. Available from: http://www. pubmedcentral.nih.gov/articlerender.fcgi?artid=137870\&tool= pmcentrez\&rendertype $=$ abstract

10. Neelakanta $\mathrm{G}$, Sultana $\mathrm{H}$. The use of metagenomic approaches to analyze changes in microbial communities. Microbiol Insights. 2013;6:37-48.

11. Yozwiak NL, Skewes-Cox P, Gordon A, Saborio S, Kuan G, Balmaseda A, et al. Human Enterovirus 109: a novel interspecies recombinant Enterovirus isolated from a case of acute pediatric respiratory illness in Nicaragua. J Virol. 2010;84(18):9047-58.

12. Houldcroft CJ, Beale MA, Breuer J. Clinical and biological insights from viral genome sequencing. Nat Rev Microbiol. 2017;15(3):183-92.

13. Liu J, Kabir F, Manneh J, Lertsethtakarn P, Begum S, Gratz J, et al. Development and assessment of molecular diagnostic tests for 15 enteropathogens causing childhood diarrhoea: a multicentre study. Lancet Infect Dis. 2014;14:716-24.

14. Jones MS 2nd, Harrach B, Ganac RD, Gozum MMA, Dela Cruz WP, Riedel B, et al. New adenovirus species found in a patient presenting with gastroenteritis. J Virol. 2007;81:5978-84.

15. Moore NE, Wang J, Hewitt J, Croucher D, Williamson DA, Paine S, et al. Metagenomic analysis of viruses in feces from unsolved outbreaks of gastroenteritis in humans. J Clin Microbiol. 2015;53:15-21 Available from: http://www.pubmedcentral.nih.gov/articlerender.fcgi?artid=4290914\&tool= pmcentrez\&rendertype=abstract [cited 2015 Feb 22].

16. Sidoti F, Ritta M, Costa C, Cavallo R. Diagnosis of viral gastroenteritis: limits and potential of currently available procedures. J Infect Dev Ctries. 2015:9:551-61.

17. Oude Munnink BB, van der Hoek L. Viruses causing gastroenteritis: the known, the new and those beyond. Viruses. 2016:E42.

18. Mo QH, Wang HB, Dai HR, Lin JC, Tan H, Wang Q. et al, Rapid and simultaneous detection of three major diarrhea-causing viruses by multiplex real-time nucleic acid sequence-based amplification. Arch Virol. 2015:719-25.

19. Yang J, Yang F, Ren L, Xiong Z, Wu Z, Dong J, et al. Unbiased parallel detection of viral pathogens in clinical samples by use of a metagenomic approach. J Clin Microbiol. 2011:49:3463-9.

20. Madi N, Al-Nakib W, Mustafa AS, Habibi N. Metagenomic analysis of viral diversity in respiratory samples from patients with respiratory tract infections in Kuwait. J Med Virol. 2018:90:412-20.

21. Zhang T, Breitbart M, Lee WH, Run JQ, Wei CL, Soh SWL, et al. RNA viral community in human feces: prevalence of plant pathogenic viruses. PLOS Biol. 2006

22. Finkbeiner SR, Kirkwood CD, Wang D. Complete genome sequence of a highly divergent astrovirus isolated from a child with acute diarrhea. Virol J. 2008;5:117.

23. Victoria JG, Kapoor A, Li L, Blinkova O, Slikas B, Wang C, et al. Metagenomic analyses of viruses in stool samples from children with acute flaccid paralysis. J Virol. 2009:4642-51.

24. Raboni SM, Damasio GAC, Ferreira CEO, Pereira LA, Nogueira MB, Vidal LR, et al. Acute gastroenteritis and enteric viruses in hospitalised children in southern Brazil: aetiology, seasonality and clinical outcomes. Mem Inst Oswaldo Cruz. 2014;109:428-35.

25. $R S M, D G A, F C E, P L A, N M B, \vee L R$, et al. Acute gastroenteritis and enteric viruses in hospitalised children in southern Brazil: aetiology, seasonality and clinical outcomes. Mem Inst Oswaldo Cruz. 2014:428-35.

26. Wilhelmi I, Roman E, Sanchez-Fauquier A. Viruses causing gastroenteritis. Clin Microbiol Infect. 2003;9(4):247-62

27. Kim KH, Yang JM, Joo SI, Cho YG, Glass Rl, Cho YJ. Importance of rotavirus and adenovirus types 40 and 41 in acute gastroenteritis in Korean children. I Clin Microbiol. 1990:28(10):2279-84.

28. Gelaw A, Pietsch C, Liebert UG. Genetic diversity of human adenovirus and human astrovirus in children with acute gastroenteritis in Northwest Ethiopia. Arch Virol. 2019;164(12):2985-93.

29. Parashar UD, Hummelman EG, Bresee JS, Miller MA, Glass RI. Global illness and deaths caused by rotavirus disease in children. Emerg Infect Dis. 2003;9:565-72.

30. Parashar UD, Gibson CJ, Bresee JS, Glass RI. Rotavirus and severe childhood diarrhea. Emerg Infect Dis. 2006;12:304-6.

31. Lanata CF, Fischer-Walker CL, Olascoaga AC, Torres CX, Aryee MJ, Black RE. Global causes of diarrheal disease mortality in children $<5$ years of age: a systematic review. PLoS One. 2013;8:e72788.

32. Tate JE, Burton AH, Boschi-Pinto C, Parashar UD. Global, Regional, and National Estimates of Rotavirus Mortality in Children <5 Years of Age, 2000 2013. Clin Infect Dis; 2016;62 Suppl 2:S96-105

33. Sethi SK, Al-Nakib W, Khuffash FA, Majeed HA. Acute diarrhoea and rotavirus infections in young children in Kuwait. Ann Trop Paediatr. 1984:4:117-21.

34. Sethi SK, Khuffash FA, al Nakib W. Microbial etiology of acute gastroenteritis in hospitalized children in Kuwait. Pediatr Infect Dis J. 1989;8:593-7.

35. Aiemjoy K, Altan E, Aragie S, Fry DM, Phan TG, Deng X, et al. Viral species richness and composition in young children with loose or watery stool in Ethiopia. BMC Infect Dis. 2019;19:53. 
36. Patterson SS, Smith MW, Casper ET, Huffman D, Stark L, Fries D, et al. A nucleic acid sequence-based amplification assay for real-time detection of norovirus genogroup II. J Appl Microbiol. 2006;101:956-63.

37. Al-Rashidi A, Chehadeh W, Szücs GG, Albert MJ. Different norovirus genotypes in patients with gastroenteritis in Kuwait. J Med Virol. 2013;85: 1611-8 Available from: http://www.ncbi.nlm.nih.gov/pubmed/ 23852687[cited 2015 mar 1].

38. Butot S, Le Guyader FS, Krol J, Putallaz T, Amoroso R, Sanchez G. Evaluation of various real-time RT-PCR assays for the detection and quantitation of human norovirus. J Virol Methods. 2010;167:90-4.

39. Lee JI, Lee G-C, Chung JY, Han TH, Lee YK, Kim MS, et al. Detection and molecular characterization of adenoviruses in Korean children hospitalized with acute gastroenteritis. Microbiol Immunol. 2012;56:523-8.

40. Li L, Phan TG, Nguyen TA, Kim KS, Seo JK, Shimizu H, et al. Molecular epidemiology of adenovirus infection among pediatric population with diarrhea in Asia. Microbiol Immunol. 2005;49:121-8.

41. Shimizu H, Phan TG, Nishimura S, Okitsu S, Maneekarn N, Ushijima H. An outbreak of adenovirus serotype 41 infection in infants and children with acute gastroenteritis in Maizuru City. Japan Infect Genet Evol. 2007;7:279-84.

42. La Rosa G, Della Libera S, Petricca S, laconelli M, Donia D, Saccucci P, et al. Genetic Diversity of Human Adenovirus in Children with Acute Gastroenteritis, Albania, 2013-2015. Biomed Res Int. 2015:142912.

43. Alcala AC, Perez K, Blanco R, Gonzalez R, Ludert JE, Liprandi F, et al. Molecular detection of human enteric viruses circulating among children with acute gastroenteritis in Valencia, Venezuela, before rotavirus vaccine implementation. Gut Pathog. 2018;10:6.

\section{Publisher's Note}

Springer Nature remains neutral with regard to jurisdictional claims in published maps and institutional affiliations.

Ready to submit your research? Choose BMC and benefit from:

- fast, convenient online submission

- thorough peer review by experienced researchers in your field

- rapid publication on acceptance

- support for research data, including large and complex data types

- gold Open Access which fosters wider collaboration and increased citations

- maximum visibility for your research: over $100 \mathrm{M}$ website views per year

At $\mathrm{BMC}$, research is always in progress.

Learn more biomedcentral.com/submissions 